\title{
EXPLORING THE CHARACTERISTIC OF PROPHETIC-LIMINALITY IN MINISTERIAL LEADERSHIP: A NECESSARY ETHIC FOR CONTEMPORARY SOUTH AFRICA.
}

\section{J SLATER}

\section{UNIVERSITY OF SOUTH AFRICA}

\begin{abstract}
This article explores the prophetic liminality of Christian leadership as it is practiced against the contextual backdrop of social, ecclesial and ethical upheavals such as secularism, relativism, sexism, corruption, violence, crime, women abuse, xenophobia, disbelief and disillusionment in authority both in church and state. It argues for an up-to-date and leading-edge church-ministerial response to modern-day situations. It proposes liminal and innovative leadership for both church and state. However, the liminal quality is specifically aligned with the prophetic dimension of leadership. A prophet's leadership is here understood as visionary leadership that challenges and directs people beyond the ordinary, and confronts that which is unethical in society. Liminal here implies being and functioning at the cutting-edge of events, trailbracing and by steering away from the conventional approaches. Sadly, because leadership had become enmeshed with the systemic designs of the church, society, economics, culture or tribe, it demands to be interjected with an exceptional characteristic to minister both directly and at the same time indirectly to problematic situations. In the words of Diarmud O'Murchu, for a leader to function liminally s/he needs to be on the doorstep or on the horizon of everything contemporary. For leaders to stay in force and relevant implies living with innovative freedom, with humandivine recklessness and with honest integrity. In turn for liminality to be an effective quality in leadership, it involves being spiritually and morally courageous and particularly attuned to a transcendent capacity. This enables the leader to move with the ever changing circumstances of our times,
\end{abstract}


into different situations and cultures, thus devising and applying different responses that constantly accommodate new possibilities The article carves out a theological and a directional itinerary for ministerial leadership that offers a liminal-prophetic liminal-transcendent challenge to leadership today. Liminal transcendent leadership pleads not to be dictated by ecclesial or social conventions and neither by personal conventions. Liminal leadership is by nature a painful search for an appropriate response to what is new, for that which is different in contemporary scenarios.

Key words: liminality, ministerial leadership, human-divine recklessness, innovative spaces and freedom, graced companionship, prophetic ministry.

\section{INTRODUCTION}

Leadership on the whole is a difficult task and to lead with the required passion in our contemporary social and ecclesial environment calls on some additional skills to assist those in church ministerial leadership. To this end, this article employs the power of liminal resilience, which will enable leaders to function influentially and inspirationally that would somewhat simplify the task of ecclesial or any other kind of leadership today. Liminality has a twofold capacity: a leader endowed with liminal competence and insights leads in a manner that promotes "fullness of life" (Jn 10:10), since it exercises the moral obligation to create an environment that enables people to engage with the necessary ingredients that fosters well-being. The task of Church leaders is to contribute to the holistic growth of members and to prevent the spiritual life of congregants to stagnate, since a dormant and the secular, materialistic, environment does violence to its members and prevents them from growing spiritually. When the spiritual life becomes incompatible with human growth, then it is a deficiency not only to society, but also to the transcendent nature of the human person. If leadership is meant to create 
Exploring the characteristic of prophetic-liminality in the ministerial leadership: A necessary ethic for contemporary South Africa

movement, if it is meant to reach out to never-ending horizons, to nomadic, shifting horizons, (a term coined by Karl Rahner (1966:230-231) referring to his "metaphysics of becoming"), then this should define church ministerial leadership as well. This article thus explores the kind of ministerial leadership that is both prophetic and liminal, and facilitates leaders to remain in a continuous state of renewal and development. This implies utilizing the liminal and transcendent capacity towards exercising mindfulness of resonant leadership (Boyatzis, and McKee 2005:71). This leadership encourages a person to move with changing circumstances, to remain open to different developments, to devise different responses to contemporary changes, to reply to new possibilities, to remain relevant and rely on the activation of- and attentive tothe Divine: thus being prophetic. The liminal aspect of leadership involves prophetic "divine-human recklessness", a term used by O'Murchu (1999:18), which implies creating innovative spaces of freedom that challenge others to live a liminal existence rather than becoming over-spiritualized and institutionalized and as a result stand to lose the prophetic capacity, the capacity for growth. Liminal and prophetic leadership is for life, the ministry and leadership that derive from this quality is life-giving, and certainly not a preparation for death.

\section{THE CONCEPTUALIZATION OF LIMINALITY IN LEAD- ERSHIP}

The term 'liminality' derives from the Latin word 'limen', which means 'threshold', to be at the 'edge' or at the 'inception', the genesis of something. Generally the word is associated with the quality of ambiguity, or transition and uncertainty. The state of liminality is depicted as a process of becoming, it is transitory, and does not offer the final answer as it is openended and it is a process of growing in awareness of something different or new. Liminality is being in a state of betwixt 
and between; amidst that which is known and unknown. Often a liminal space is described as a space created in a transition phase of life, where a person is neither in the previous stage and not yet in the stage to come. This is often referred to a period of initiation or transition, a unique spiritual position of "unknowing". This space is fluid and flexible and enables the person to be free to say what s/he would normally not say, and do what she would normally not have the courage to do.

Liminal leadership implies leadership at the margins, shuttling between the periphery and centre, between the known and the unknown. It is not prescriptive, but encounters the situation as it surfaces. It implies working through the contradictions and frustrations of both those in leadership and those who are being lead, but with an openness to the unexpected without any expectations.

Because life situations are always changing, people's circumstances are constantly in a state of flux, nothing is therefore certain and fixed. The term liminal has broadened from its original meaning to portray political, cultural, social and religious changes and rituals. People are living in liminal spaces of all kinds, and consequently social, political, religious and cultural hierarchies are often reversed or temporarily dissolved; the continuity of tradition is uncertain, and future outcomes, that were taken for granted, are thrown into doubt. Where there existed perceived order, creative chaos generally takes over and within the time of liminality, the state of fluidity enables new institutions and practices to come into being. It is these circumstances that call for liminal leadership, because it has to serve or minister to people that also live and function in liminal conditions. Liminal conditions require liminal leadership styles and methods that respond to the flux and fluidity of the statuses of present-day life. 
Exploring the characteristic of prophetic-liminality in the ministerial leadership: $A$ necessary ethic for contemporary South Africa

Leadership, while also in a state of liminality, has to lead to, and in and from liminal situations and to do so, implies dealing with uncertainties. A liminal leader is therefore meant to lead people out of liminal spaces of uncertainty, or alternatively assist people to feel at home with liminal situations. Liminal leadership has to lead people to wholeness in such circumstances and from a psychological perspective Jung (1953:137) stated that the individuation process of self-realization takes place within liminal spaces. It begins by withdrawing from the normal modes of socialization and move from disorientation to integration. What takes place in the uncertain phase of liminality is a process of breaking down, and this happens in the interest of its permanent accessibility as the source of creative power.

Major transformations occur in liminal places, because liminality, being so variable can pave the way to access esoteric knowledge or understanding on both sides of the spectrum. In this sense liminality is sacred, alluring and dangerous, and this draws leadership to different heights and expressions. Leadership has to take that transcendent leap so as to be versatile and pliable to all circumstances. This is what liminality offers leadership, that unique spiritual position, and in a prophetic sense it means that liminal leadership needs to be attuned to the signs of contemporary times. The challenge for liminal leadership is particularly pivotal in our times that are marked with ecclesial and ethical upheavals such as secularism, relativism, sexism, corruption, violence, crime, women abuse, xenophobia, same sex marriages, homo-parentality, disbelief and disillusionment concerning those in authority both in church and state. In these controversial circumstances liminal leadership will caution not to respond with inappropriate dogmatic resolutions, neither by moralizing, or spurting forth unhelpful biblical doctrine, but to look at what 
constitute responsible and appropriate responses, which may not necessarily include answers or solutions, but a willingness to linger with those who find themselves in liminal spaces of uncertainly. To accompany and remain with the people at the thresholds of waiting and unknowing.

\section{CHURCH MINISTERIAL LEADERSHIP: A LIMINAL EN- TERPRISE}

For ministerial or ecclesial leadership to be liminal, as stated above, requires divine-human recklessness and the creation of innovative spaces and freedom. Liminality offers mobility, or freedom of movement and pioneering spaces. Charles, La Shure (2005:7) explains the freedom as the ability to move back and forth between states and areas. To go out of a situation and go back into it again. When applying the characteristics of liminality to the practice of leadership, it is clear that liminal persons possess a freedom, which non-liminal individuals do not have. Liminal persons can impress their leadership on people and situations freely, while with non-liminal persons, it is the other way round, they are "imposed upon" by situations and people. It is not possible for a liminal person to remain static within a given social, political, religious or cultural structure. The more a person gets integrated into a structure, the more the person loses his or her ability to be liminal. The flip side of losing liminality is to gain stability, but stability imparts stagnation and often sacrifices creativity.

By the same token, whereas the Christian Life is a constant liminal undertaking, it should always lurk towards the outeredge of social and ecclesial existence. Inspirational Christian Ministerial leadership inspires others in leadership and people in general to be always at "the hem of the garment of Jesus." Unfortunately, in many instances ministers and Chris- 
Exploring the characteristic of prophetic-liminality in the ministerial leadership: A necessary ethic for contemporary South Africa

tian leaders had allowed themselves to become heavily domesticated and excessively observant to the conventions of the institution. Christian Ministerial leaders have assumed tendencies whereby they are over-identified with orthodox ecclesial life designs. This article argues for the view that Christian ministers and clergy cannot be liminally prophetic if they had become and remain enmeshed with the systemic designs of the church, society, culture or nationality. This seriously hinders the ability to lead in a liminal and prophetic manner. In the words of O'Murchu (1999: 18) for a leader to function liminally s/he needs to be on the threshold or on the horizon of everything contemporary. For Christian ministerial leadership to remain effective and relevant implies living with innovative freedom, with human-divine recklessness, (the ability to take risks) and to minister with integrity. The Liminal - ministry cannot be dictated by ecclesial or social conventions and neither by personal conventions, but needs to be spiritually open to the Divine and prophetically courageous to go against the flow of the secular stream. This liminal-transcendent capacity enables one to move with and within changing circumstances, into different situations and cultures, to devise different responses, to reply to new possibilities in other words, to be Spirit-driven.

\section{THE DIVINE-HUMAN ARRANGEMENT OF CHRISTIAN MINISTERIAL LEADERSHIP}

Ministerial leadership, to be precise Christian Ministerial leadership, is different from corporate leadership in the sense that it has a divine-human purpose and its human management structure should support this divine purpose inherent of prophetic leadership. While there is no uniform definition of prophetic leadership in place, Christian leadership can nevertheless be described as having a sustainable leadership style that gives form to the vision and mission while staying faithful 
to the divine mission of the Church of Jesus Christ. The prophetic nature of this type of leadership is that it "leads and inspires" simultaneously. While leadership in all its forms is a personal challenge and responsibility, the ministerial leadership, typical of the Christian life, is that which is fixed upon the person of Jesus. It is a spiritual leadership that draws its prophetic strength from contemplative listening to the Word of God. It is an "attentive leadership" because the art of habitual listening aligns the leader to the discerning movements or gentle stirrings of the Spirit.

Christian Ministerial leadership models its governance on the transformational leadership of Jesus: a leadership that offers vision, spiritual energy, challenge and courage to those called to minister to of God's people (Doohan 2007:11). This implies absorbing and imbibing Jesus' way of leading by ministering in the face of political and social turmoil and general disillusionment with the Christian Church by calling upon the Spirit's lead in the evolving nature of ecclesial life by seeking wisdom in exploring how to lead more fully as Jesus led his companions in a graded manner (Garvin 2013: 3).

\section{LIMINAL-PROPHETIC LEADERSHIP AS GRACED-COM- PANIONSHIP, NOT MANAGEMENT}

To formulate a definition of leadership, especially prophetic leadership, in this our post-modern world, is not an easy task, because leadership is something everyone knows about, but to exercise leadership with authority and inspiration is more complex. To lead with authority and inspiration implies being willing to recognize the wisdom and inspiration of others (Dorr 2006:10). Leadership is a phenomenon that impacts everywhere and specifically on people's lives. Hence, for the purposes of this argument, leadership is illustrated by looking at the prophetic leadership of Jesus Christ by employing the 
Exploring the characteristic of prophetic-liminality in the ministerial leadership: $A$ necessary ethic for contemporary South Africa

term "graced companionship" as is used by Mary Pat Garvin (2013:3) to describe the leadership approach of Jesus. Mary Pat Garvin maintains that to lead as a "graced companion" is to believe that leadership is first and foremost about the relationship and secondly, that leadership is a shared or communal venture. A prophetic leader capable of "graced companionship" possesses a heightened capacity for "mature, healthy (that is holy) relationships with others. Garvin says that "interpersonal intelligence" (a term used by Howard Gardner 2006:6) is the first and foremost quality of an effective leader, a leader capable of graced companionship.

To clarify prophetic leadership, it is therefore necessary to distinguish it from the perception that ministerial leaders had become efficient "managers or executive officers". While management is a very useful skill, traditionally it is distinguished as the cognitive operation of getting activities completed effectively with and through other people, this, nevertheless, is not leadership. Contemporary scholars, such as John P. Kotter (2006: 370-381), define leadership-management as coping with (human) complexities. To manage complexity is first done by planning, determining goals for the future and establishing steps to reach the goals and objectives. It likewise does so by organizing its staffing, creating organizational structures and the accomplishment of plans is done by controlling and problem solving, monitoring results by means of reports and meetings (Kotter 2006:7). Management, thus, entails the processes of planning, organizing, leading and controlling the resources of an organization and this is done as productively as possible. Planning includes establishing goals, strategies and coordinating activities. The primary aim of management is therefore to ensure that the goals and purposes of an organization are achieved. While this may be useful to commercial enterprises, but for Christian 
governance in a liminal-prophetic leadership, it is the emphasis on a divine-human arrangement that makes the task a grace-filled responsibility.

Leadership in general brings about change by setting direction and developing a vision along with strategies to achieve the vision. According to Kotter (2006:7) leadership aligns people by means of communicating the new direction to understand the vision and its implementation. To accomplish the vision requires motivating and inspiring, keeping people moving in a forward direction, despite obstacles to change, but by "appealing to basic, but often untapped human needs, values and emotions". Leadership is thus not so much about management techniques, movements and strategies, however helpful, but instead a matter of focal point and perspective, interpreting and providing direction. The word manager was not used by Jesus in the manner that we use it today; instead he used the word steward. In the biblical sense the word steward, manager or guardian of a household share the same Greek source or root, namely oikonomos (Luke 16:2$3)$. Management in the biblical sense implies handling the affairs of the household on behalf of the head of the house. Jesus made many references to the steward as one who is accountable to God for his/her actions and results. To be a steward-leader involves offering one's time, talents and treasure in the service of the Lord.

To provide the theological understanding of prophetic stewardship and leadership, it is therefore essential to obtain clarity between the different meanings and understandings of the two concepts: leadership and management, even though they are not mutually exclusive. Leadership can be described as the development and articulation of a shared vision, motivating the key people without whom that vision cannot become a reality, and gaining the cooperation of most members 
Exploring the characteristic of prophetic-liminality in the ministerial leadership: A necessary ethic for contemporary South Africa

involved. When it comes to liminal-prophetic-leadership, it implies that leaders model the way, not by words, but by setting the example through daily actions that demonstrate their committed beliefs (Kouzes and Posner 2008:27).

Liminal-leadership is inspired by a shared vision and it gazes across the horizon of time. These leaders have a desire to make things happen, to change the way things are, to create something that no one else has ever created before. Because liminal leadership is person oriented, these leaders make sure that they have intimate knowledge of people's dreams, hopes, aspirations, visions and values (Kouzes and Posner 2008:2). Liminal leaders breathe life into the hopes and dreams of others and enable them to see the exciting possibilities that the future holds, they inspire people to move to the edge of possibilities. They ignite the flame of passion in others by expressing enthusiasm for the compelling vision and charisma of their groups or congregations. Liminal leaders, venture out into cutting edge service, they see revolutionary opportunities to start up new and innovative as well as groundbreaking initiatives. All leaders and in particular liminal leaders challenge the processes. Liminal leaders are innovators, "people who are willing to tread out into the strange" and for this reason they search for opportunities to innovate, grow and improve, and innovation comes more from listening rather than from instructing. To listen and observe dramatic external events can be the catalyst that thrusts an organization or congregation into a radically new condition. And in such a case the primary contribution of the leader is to spot and hold up good ideas, and a willingness to challenge the systems, procedures and services. Liminal leaders embark on innovation and change by involving experimentation, risk and failure. They thrive on little victories and so build confidence to the point that big challenges can be met. 
The basic curriculum of a liminal leader is the art of facing obstacles and problems. A liminal leader learns from both failures and successes (Kouzes and Posner 2008:30). Exemplary leaders strengthen every person's capacity to do good and to deliver; they too encourage the affection of their ingredients. Liminal leadership is ultimately a relationship between those who aspire to lead and those who choose to follow. Kouzes and Posner (2008:30) are of opinion that success in ordinary leadership is entirely dependent on the capacity to make and keep up those human relationships that enable people to produce extraordinary things done on a steady basis. It employs the ability to enable others to work by fostering collaboration and by promoting cooperative goals and building confidence, as well as strengthening others by sharing power and free will. By always recognizing and affirming the contribution made by the other and by showing appreciation for individual excellence is to boost the heart by celebrating the values and victories and thereby producing a feeling of community. By comparison liminal and prophetic leadership based on the leadership of Jesus Christ is to exercise the ability to intuit the emotions, ideas, desires and aspiration of others as Jesus did simply, because He was so attuned to his own interior or spiritual life. Graced companionship requires a spirituality that sustains leadership, in particular liminal and prophetic leadership.

\section{The transcendent that nurtures liminal-prophetic lead- ership}

Liminal-prophetic leadership is enhanced by an active spiritual life that assists the leaders to move from self-fulfillment to self-transcendence. Spirituality is often mistakenly associated with religion, which it is not. Instead spirituality is each 
Exploring the characteristic of prophetic-liminality in the ministerial leadership: $A$ necessary ethic for contemporary South Africa

individual's exploration of the transcendent and how that plays out in his or her spirit and leadership. To practice liminal leadership, inner spiritual health matters. Christian leadership operates out of a spirituality that fosters personal integration, nurtures through reflection, contains a communal dimension, is balanced and moves the leader to compassionate action. A practicing spirituality sustains prophetic liminal leadership; the leaders gain numinous strength deriving from the awareness of the transcendent nature of the Gospel together with the art of contemplation. Prophetic liminal leadership integrates liturgy and work, prayer and service, faith and action. The aim of Christian ministerial leadership is to endeavour at all times how to blend the active life with the contemplative in a meaningful way, to be attentive to the motions of God and discern what Christ would desire in a given situation. It is through relationships created and nourished between the Divine and the leader, and the relationship between leaders and members that liminal-prophetic leadership is unleashed. Without this accompanying and developing spiritual inner self, without the transcendent element, even ordinary leadership goes astray and this is evident in continuous scandals committed by religious ministers, church, government and private sector organizations. In the same vein, the moral character of leadership also mat- 
ters immensely. Spiritual intelligence, just as relational intelligence, is the positive force that drives liminal leadership. This spiritual intelligence is conceptualized by Amram and Dryer (2007:17-20) and it involves:

- Experiencing meaning through a call for service

- Using ways of knowledge and states of consciousness beyond linear thought such as prayer, meditation, silence and intuition).

- Aligning with essence, the sacred, divine, or universal life force.

- Sensing and seeking wholeness, unity, and interconnection between all things

- Living consciously with intention and mindful presence

- Being openly curious and accepting of reality (including the negative and shadow sides of life)

- Appreciating positives: faith, hope, gratitude and optimism

- Nurturing relationships with respect, empathy, and compassion towards self and others

- Displaying responsible freedom from conditioning, attachments and fears

- Acting with integrity and a clear code of values

- Possessing humble receptivity and openness

Andre L. Delbecq (2008: 487-488) is of opinion that spirituality consists of both a worldview and a path. The worldview may 
Exploring the characteristic of prophetic-liminality in the ministerial leadership: $A$ necessary ethic for contemporary South Africa

be formed by great wisdom traditions or a mixture of spiritual insights; theistic, non-theistic or transcendent, but it is always intertwined with a person's life history, experiences, upbringing, personality and a sense of self. This worldview becomes the inner compass that informs action. The path Delbecq (2008: 487-488) describes as "the set of disciplines (prayer, meditation, reflection, worship, ascetic practice)" that over time frees the individual from tyranny of the false self - the shadow side- so that fear anxiety, greed, and hubris (excessive pride and ambition) no longer dominate behavior and choice". Be, as it may, there is a definite link between spirituality and leadership effectiveness.

\section{Spirituality inspires leadership}

A spirituality that inspires leadership is motivated by a strong sense of calling and the unfolding of the calling is a mysterious process. This calling is an intersection between a person's gifts and the needs of society or a specific community. In the words of Delbecq (2008 487-488) a leader's becoming precedes the doing: it takes long periods of preparation, skills development, setbacks, failures, seeing, waiting and delayed gratification. The developmental as well as liminal periods prepares the leader to know themselves and compassionately identify with unmet human needs. Their combination of personal integration, authenticity, human care and actions inspires others to join them in the search for complex answers. Leadership in general requires an integrated self, a conversion from a false self that is trapped in fear, greed and distortion to a true self steeped in compassion and integrity. Followers (those who function under the leadership of another) support and are impressed by leaders who stick with a vision that address significant human needs and is forced by a deep sense of missionary work (Delbecq: 2008: 487-488). Their 
true vision conveys a larger human meaning and there is a spiritual power in that realization.

Spiritual integration involves learning self-love, differentiating it from narcissism, and developing capacities to fully love and embrace others. This implies that the one, who is missioned or endowed with leadership, cares for his or her own spiritual, emotional, relational and physical well-being, since this is in service of carrying out the task entrusted to him or her. Since effective leadership is communal and shared: it is also collaborative. This implies involving others in decision-making processes and those affected by the decision-making, but liminal-prophetic leadership goes far beyond communal and shared leadership, it takes on the quality of 'generativity'. This means making provision for those in one's leadership care to develop their own capacities for liminality and leadership. Generativity is about being in contact with that innate movement within oneself, to be in touch where the spirit touches us to activity.

The process of purgation, and illumination and unification repeat itself in the life of a leader. Purgation rids the self of flaws like greed, ambition and lust for power. Illumination opens the mind to the laws of spiritual functioning and unification is a sense of the divine, others and all of creation. For the leader to drive attention away from the self, to diminish the messages of the ego and to place the mystery of the spirit and the needs of others in the foreground, is part of the spiritual integration process of the leader's becoming and doing.

Delbecq (2008: 494) is of opinion that leaders trained in the Christian tradition, progress by embracing the gifts of the Spirit: namely wisdom, understanding, counsel, fortitude, knowledge and fear of the Lord in their spiritual journey. Ac- 
Exploring the characteristic of prophetic-liminality in the ministerial leadership: $A$ necessary ethic for contemporary South Africa

cording to Delbecq leaders who abide by these spiritual disciplines and mediation developed qualities that benefited them in their tasks such as:

An improved capacity to listen and less of a need to dominate

- More patience with others, thus less judgmental and self-asserting

- Greater adaptability and less desire to control others

- Greater focus and less distraction and anxiety

- Greater ability to devote self to service through work and less frustrations with burdens and irritants at work

- More hopefulness and joyfulness even in times of difficulty and less cynicism and pessimism

- Greater overall serenity and trust

- More confidence in using personal competencies and deeper knowledge of self-limitations, more trust that things will work out

- Persistence and diligence and less withdrawals and self -occupation when under stress (Delbecq (2008: 494).

Delbecq is of opinion that these qualities are acquired by spiritual practices, which assist leaders to remain faithful in the difficult requirements of subsidiarity: the deep involvement of others in self-forbearance in building consensus, negotiating conflicts, and engaging in ethical and moral judgments. Delbecq (2008: 495) says that subsidiarity requires times of reflection to evolve the necessary intuitive and non-linear 
thinking processes and the humility to remain open to others. He says: "Being the change you wish to lead" is not easy and not the territory for the spiritually immature. The liminal leaders who travel the spiritual journey have acquired the ability to better facilitate strategic decision-making, which is a central task of leadership.

A practical and practiced spirituality is a preordained prerequisite for liminal Christian leaders, whose task is to create communities that foster human dignity. Their lived or practical spirituality steers the task of leadership to a noble purpose and infuse the ethos of those who are led to their greater sense of calling and create cultures that endorse participatory decision making processes (Delbecq 2008: 496). Spiritually mature leaders to accept and to be present to the truth of their own limitations and the restrictions of others. They can create a solid community, despite human imperfections and they can see in others the gifts that offset any weaknesses. A culture where the imperfection of the human condition is accepted and individuals are embraced and respected for who they are, is liberating and motivating. Harsh judgment is replaced by love and we know when we are loved as opposed to be used and appreciated only when things go well. There is no need for fear, anxiety, self-protection, or blame when we are accepted by the leader in the fullness of our human condition (Delbecq 2008: 499). In fact a liminal leader outgrows his or her own suffering, insecurities and the need for acceptance.

\section{CHALLENGES OF LIMINAL-PROPHETIC LEADERSHIP}

The conclusion sums up the challenges of liminal-prophetic leadership. The first challenge of liminal leadership is to adopt a prophetic expression for Christian life witness and commitment. In other words, if the prophetic dimension of 
Exploring the characteristic of prophetic-liminality in the ministerial leadership: A necessary ethic for contemporary South Africa

Christian life is visible, then prophetic leadership comes easier.

\section{The challenges are:}

Liminal-Prophetic ministerial leadership is vision-filled. Without the clarity of vision together with an understanding of principled leadership, liminality cannot be employed. A clear vision of leadership that embraces liminality provides the leader with the freedom to move from the known to the unknown and vice versa. The prophetic leader displays a spiritual maturity and an awareness of the holiness of the Divine. This sense of God's holiness is central to prophetic leadership.

The particular challenge that accompanies this characteristic is that the leader has to have a personal understanding of the essential prophetic nature of his/her own calling.

Liminal-Prophetic ministerial leadership is inspirational. The visionary outlook of the Christian leader is inspired by the Gospel, the charisms of the Holy Spirit. This is kept alive by authentic integration of contemplation and the consciousness of the presence of God. The utilization of divine-human recklessness is what provides the liminal dimension to inspirational leadership. It also assists leaders to instill inspiration in the ones that they lead. Important for inspiration is the ethical integrity of the leaders that creates trust.

The challenge here is to keep abreast with the current development and movements of the Holy Spirit in the life of the Church and World. It requires personal openness to move along with the promptings of the Spirit of Christ in a liminal fashion, meaning that it is not static, but constantly in motion. 


\section{Liminal-Prophetic ministerial leadership is potentially} conflictional. It confronts establishments and authorities: be they the church, state or ministers congregations, society or cultures. Liminal-Prophetic leadership militates against institutionalization, legalization, clericalism, routine. Institutionalization in particular destroys a prophetic spirit, but liminality provides the life-giving aspect. Something that is always moving has the potential to be conflictional as it disturbs the mundane and the intimate.

The challenge here is whether the leader is prepared to confront power systems and offer an alternate vision and worldviews and move to the edges.

\section{Liminal-Prophetic ministerial leadership displays a God-} consciousness, and God-consciousness is always a renewed consciousness. This renewed consciousness is meant to keep lives of ministerial leadership pertinent. A new consciousness has to be created around the minister's life since it is an undertaking, a mission in motion and not an establishment or an institution.

The challenge here is to transcend the reliance on constitutions, rules and regulations for relevance, but to be open to the Holy Spirit. As a movement the minister's life needs fluidity, creativity and courageous abandonment to divine recklessness.

\section{Liminal-Prophetic ministerial leadership is emancipa-} tory. It frees others and self from exploitation and destruction. The liminal dimension makes provision to move from the destruction and exploitation of the new and innovative. It needs to risk witnessing to alternatives to the status quo in societies, cultures, world and the church. This may imply creating alternate ethical scenarios, communities of conscience, and these communities by their very existence are prophetic. 
Exploring the characteristic of prophetic-liminality in the ministerial leadership: A necessary ethic for contemporary South Africa

The challenge here is to veer away from the temptation of legislative leadership that enchains people and become more conducive to prophetic mission and ministry.

\section{Liminal-Prophetic ministerial leadership is accountable.}

Leadership is exercised with the cognition that all are equal and this calls for mutual accountability. Accountability here in the manner of stewardship that takes liminal responsibility and risks to embark on that which is new and unknown.

The challenge here is to see that ministers and the Church are first and foremost accountable to the People of God and not the other way round. The responsibility to be accountable is not marked by domination, control and power, but by trust and empowerment of the other.

\section{Liminal-Prophetic ministerial leadership is counter-cul-} tural as it steers away from the dominant social consciousness of leadership. Leadership in this instance is servant leadership, shepherd leadership. Living the commitment of prophetic ministerial leadership can be a vital critique of the social wickedness, which diminishes human dignity.

The challenge here is to obtain an understanding and responsibility of the liminality of ministerial life. The purpose of liminality is to expand our horizons, not contract them. It is healthier to imbibe the spirit of liminality, to integrate the spirit thereof, rather than becoming obsessed with fitting into the clear-cut parameters of social, cultural and ecclesial expectations. 
Liminal-Prophetic ministerial leadership in the African context has to produce an authentic manifestation of indigenous prophetic Christian living by taking into account the diversity of cultural values.

The challenge here is to steer away from conformist expectations that all need to be the same and the necessity to filter traditional customs and norms through the lenses of gospel values and human rights. Liminal and prophetic leadership is based on vision and values, unleashing passion and courage for leadership that requires both leader and those led to move to the periphery of newness.

\section{CONCLUSION}

Liminal leadership is leadership in motion, in search of appropriate responses. It does not reach finality, it is not static and complete. By its very nature, it endeavours to intensify the values of good leadership, to enhance the values of credible leadership and radiates the values in the ecclesial community and society as a whole. It elevates that which is already in existence by bringing it to the frontier, to the threshold, to the edge. It asks the great questions, and says the things that are often uncomfortable to say and says it on behalf of those who do not say it, who cannot say it. Liminal leadership does the things that are not generally done, says the things that are not said. It debases status and self aggrandizement. It does not elevate the leader, but the task, and for this reason it is separated from the norm, because it is not conventional in the sense that it does not follow prescribed methods and rules. It tries to restore the sacredness of leadership, by being there on behalf of the other and it does not claim to have the final answer. Often the liminal space is created by spiritual exercises and spiritual practices that inform liminal leadership. 
Exploring the characteristic of prophetic-liminality in the ministerial leadership: A necessary ethic for contemporary South Africa

If ecclesial or Christian ministerial leaders lack the energy to go where the minister's mission calls them, i.e. to the edge of the horizon, to the nomadic horizons of Being (Rahner 1978:120) then Christian leadership needs to be prepared to function outside of relevance. As a service, Christian leadership needs to become energetic, spiritually enthusiastic and full of human-divine strength. According to the theology of liminality, there will always be liminal places and liminal people. If Christian ministry, and the life of Christians, is no longer capable of responding to prophetic-liminality, then it will take on redundancy and alternate movements, which are surfacing within and outside the ministerial life context, will respond to the missing link of contemporary Christian leadership. Christian leaders need to remain enablers of their members so as to embrace prophetic moments within the Church and rediscover the significance and relevance of the Christian life and Christian Ministerial leadership.

\section{Bibliography}

Amram, Y and C. Dryer 2007. The Seven Dimensions of Spiritual Intelligence. An Ecumenical Grounded Theory. Paper presented at the 115th Annual Conference of the American Psychological Association, San Francisco, C.A. August 17-20-2007

Amram, Y. 2009. The Contribution of Emotional and Spiritual Intelligences to Effective Business Leadership. Unpublished doctoral dissertation, Institute of Transpersonal Psychology, Palo Alto, CA.

Boyazis, R and A. McKee. 2005. Resonant Leadership. Renewing yourself and connecting with others. Through mindfulness, hope and compassion. Boston: Harvard Business School Press.

Delbecq, A.L. 2008. Nourishing the soul of the Leader: Inner Growth Matters (in Gallos, J.V. 2008. Business Leadership. San Francisco: Jossy-Bass) 486-503. 
Doohan, L. 2007. Spiritual Leadership: The Quest for Integrity. Mahway, NJ: Paulist Press.

Dorr, D. 2006. Spirituality of Leadership: Inspiration, Empowerment, Intuition and Discernment. Dublin, Blackrock, The Columba Press.

Gallos, J.V. 2008. Business Leadership. San Francisco: Jossy-Bass.

Gardner, H. 2006. Changing Minds. The art and science of changing our own and other people's minds. Boston, MA. Harvard Business School Press.

Garvin, M.P. 2013. Graced Companionship: A metaphor for Religious Leadership Today. An unpublished paper given to Religious Leaders.

Kotter, P. J. 2008. Leading Change: Why Transformation efforts fail (in Gallos, J.V. 2008. Business Leadership. San Francisco: JossyBass) $370-381$.

Kouzes, J.M. and B.Z. Posner. 2004. Christian Reflection on Leadership Challenge. San Francisco: Jossy-Bass.

La Shure, Charles, "What is liminality/", 18 October 2005. URL: http://www.liminality. org/about/whatisliminality/

O'Murchu, D. 1999. Poverty, celibacy and obedience: radical option for life. New York,: Crossroad Publishing Company.

Rahner, K. 1966. Theological Reflections. Vol.4. London, Darton, Longman and Todd.

Rahner, K. 1978. Foundations of Christian Faith: An introduction to the idea of Christianity. New York: Seabury Press. 